\title{
ANALISIS MAKNA KONTEKSTUAL BAHASA DALAM IKLAN CAT TEMBOK DI TELEVISI
}

\section{ANALYSIS OF LANGUAGE CONTEXTUAL MEANING IN WALL PAINT ADVERTISEMENTS ON TELEVISION}

\author{
Dwi Ira Ningrum Ana Mardiana \\ Universitas Brawijaya \\ diraningrum09@gmail.com
}

\begin{abstract}
ABSTRAK
Penelitian ini fokus terhadap analisis makna kontekstual bahasa dalam iklan cat tembok yang ada di televisi. Adapun rumusan masalah yang terdapat dalam penelitian ini adalah bagaimanakah makna kontekstual yang terkandung dalam bahasa iklan cat tembok yang ditayangkan di televisi-televisi Indonesia?. Penelitian ini menggunakan metode deskriptif kualitatif. Iklan cat tembok yang diteliti pada penelitian ini adalah Elastex Waterproof, Aquaproof, dan Dulux. Hasil dari penelitian ini adalah makna kontekstual yang terkandung dalam tiga iklan cat tembok yang telah diteliti ini berupa kata dan juga kalimat yang berfungsi untuk menarik minat para pembeli cat tembok. Selain meyakinkan pembeli bahwa produk cat tembok tersebut memiliki kualitas yang baik, pada setiap akhir iklan terdapat pernyataan persuasif guna meyakinkan calon pembeli.
\end{abstract}

Kata kunci: makna kontekstual, iklan, televisi.

\begin{abstract}
This research focuses on analyzing the contextual meaning of language in wall paint advertisements on television. The research question of this study is how is the contextual meaning contained in the wall paint advertisement on Indonesian television?. This study used descriptive qualitative method. The wall paint advertisements studied in this study were Elastex Waterproof, Aquaproof, and Dulux. The result of this study are contextual meanings contained in three wall paint advertisements that have been studied in the form of words and setences that function to attract the buyers. In addition to convicing buyers that the wall paint product are in good quality, and at the end of each ad three is a persuasive statement to convince the potential buyers.

Keywords: contextual meaning, advertisement, television.
\end{abstract}

\section{PENDAHULUAN}

Pada zaman modern seperti saat ini untuk memasarkan barang tidaklah sulit, karena kita dapat memasang produk iklan yang akan dijual di suatu media, baik media cetak, maupun media elektronik. Iklan merupakan sebuah wadah bagi para produsen untuk memasarkan produk yang akan dijual kepada para calon konsumennya. Jadi bisa dikatakan bahwa keberhasilan penjualan sebuah produk tergantung bagaimana iklan dari produk tersebut diberikan kepada calon konsumen. Bahasa iklan diciptakan dengan unik, singkat, dan selalu terdiri dari kata-kata baru yang bisa membuat calon konsumen tertarik untuk mencoba dan 
Tuah Talino

Tahun XIV Volume 14 Nomor 2 Edisi 4 Desember 2020

ISSN 0216-079X E-ISSN 2685-3043

Balai Bahasa Kalimantan Barat

membeli produk yang sedang dipasarkan. Penyampaian iklan yang secara tepat dapat dilihat langsung oleh para calon konsumen adalah media televisi. Pada media ini para calon konsumen dapat melihat langsung bagaimana bentuk dan rupa dari produk yang akan mereka beli, perpaduan antara gambar dan kata-kata dapat memengaruhi para calon konsumen untuk membeli dan mencoba produk tersebut.

Pada penelitian ini, penulis tertarik untuk menganalisis makna kontekstual bahasa yang terdapat pada iklan cat tembok yang ditayangkan pada televisitelevisi di Indonesia. Menurut Kamus Besar Bahasa Indonesia (KBBI) makna kontekstual merupakan makna yang mengacu pada konteks, atau suatu kalimat yang dapat mendukung kejelasan dari sebuah makna. Semantik dan makna adalah dua istilah yang tidak dapat dipisahkan satu sama lain, sebab objek kajian dari semantik adalah makna. Menurut Kamus Besar Bahasa Indonesia (KBBI), makna merupakan maksud dari penulis maupun pembicara, jadi makna lebih menyangkut ke dalam segi ujaran. Hal ini dikarenakan bahasa dapat digunakan dalam berbagai kegiatan dan keperluan bermasyarakat, maka makna bahasa menjadi bermacammacam apabila kita lihat dari segi ataupun pandangan yang berbeda (Chaer, 2007: 289).

Kajian semantik yang mengkaji tentang makna ini terdiri dari tiga jenis yaitu semantik leksikal, semantik gramatikal, dan semantik maksud (makna kontekstual). Semantik leksikal (makna leksikal) merupakan makna yang dimiliki atau yang ada pada leksem tanpa konteks apapun. Misalnya leksem kucing memiliki makna leksikal 'sejenis binatang berkaki empat yang dapat mengeong'. Makna leksikal adalah makna yang sebenarnya, makna yang sesuai dengan hasil observasi panca indra kita, makna yang sebenar-benarnya (Chaer, 2007: 289).

Semantik gramatikal (makna gramatikal) merupakan makna yang baru ada kalau terjadi proses gramatikal, seperti afiksasi, reduplikasi, komposisi, atau kalimatisasi. Misalnya pada afiksasi prefiks ber- pada kata dasar sepeda menimbulkan makna gramatikal 'mengayuh atau mengendarai sepeda'. Contoh lainnya, proses komposisi dasar sate dengan dasar ayam menghasilkan makna gramatikal 'bahan', dengan dasar Madura menghasilkan makna gramatikal 'asal'. (Chaer, 2007: 290).

Semantik kontekstual (makna kontekstual) adalah makna sebuah leksem atau kata yang berada di dalam suatu konteks (Chaer, 2007: 290). Makna konteks juga berkaitan dengan situasinya, yaitu tempat, waktu, dan lingkungan penggunaan bahasa tersebut. Makna dapat diartikan dengan berbagai macam arti sesuai dengan cara kita memandang makna tersebut.

Pada penelitian ini, penulis akan lebih menekankan pada makna kontekstual pada iklan cat tembok yang ditayangkan di televisi. Jadi, bagian ini akan dibahas lebih mendalam tentang makna kontekstual. Kontekstual mengacu pada konteks, yaitu bagian dari suatu uraian atau kalimat yang mendukung atau dapat menambah kejelasan makna dan situasi yang ada hubungannya dengan suatu kejadian (KBBI). Untuk memahami suatu ujaran kita harus memahami dulu konteks situasinya. 
Hymes dalam Hasan (2010) mengemukakan faktor-faktor yang menandai terjadinya sebuah peristiwa komunikasi yaitu sebagai berikut:

S: Setting atau scene, merupakan tempat bicara atau suasana bicara.

P: Partisipan, terdiri dari pembicara, lawan bicara dan pendengar.

E: End atau tujuan.

A: Act, merupakan suatu peristiwa ketika seseorang pembicara sedang menggunakan kesempatan berbicaranya.

$\mathrm{K}$ : Key, merupakan nada suaradan ragam bahasa yang dipergunakan dalam menyampaikan pendapatnya dan mengemukakannya di depan umum.

I: Instrument, merupakan alat untuk menyampaikan pendapat.

$\mathrm{N}$ : Norma, yaitu aturan permainan yang harus ditaati.

G: Genre, merupakan jenis kegiatan diskusi.

Dari pemaparan di atas dapat disimpulkan bahwa sebuah kata atau simbol dari ujaran tidak akan bermakna apa-apa jika terlepas dari konteks. Perhatikan makna kata jatuh dalam kalimat-kalimat berikut!.

(1) Ali jatuh dari pohon mangga.

(2) Amir jatuh dalam ujian yang lalu..

(3) Anita jatuh cinta pada tetangganya sendiri.

(4) Beberapa waktu yang lalu, harga bawang merah jatuh di pasaran.

Pada setiap kalimat di atas, kata jatuh memiliki makna yang berbeda-beda sesuai dengan konteks kalimatnya.

Penelitian ini mengangkat makna kontekstual pada iklan cat tembok yang ada di televisi. Pengertian iklan sendiri merupakan penawaran atau pesan dari suatu produk atau jasa yang ditujukan kepada khalayak lewat media (Rachmadi, 1993: 36). Pihak dari pemasang iklan tersebut menggunakan bahasa yang terkesan unik untuk membujuk para calon konsumen untuk membeli atau menggunakan barang dan jasa yang ditawarkan.

Seiring dengan berkembangnya zaman, periklanan mengalami kemajuan pesat. Hal ini tentu saja juga didukung oleh teknologi yang maju. Apabila pada zaman dahulu iklan hanya dimuat pada media cetak, namun sekarang ini iklan bisa ditampilkan pada media elektronik seperti televisi. Televisi merupakan media paduan dari audio dan visual, dengan begitu para penonton bisa dapat melihat secara jelas barang yang akan mereka beli dan gunakan. Jefkins (1997: 20) mengemukakan bahwa komunikasi yang efektif selalu ditentukan oleh perpaduan kata-kata dan gambar, dengan demikian media televisi merupakan sarana yang tepat untuk menyampaikan sebuah iklan.

Para produsen dari cat tembok yang terdapat di televisi, menggunakan bahasa yang unik agar mudah diingat oleh para konsumen. Salah satunya adalah iklan cat tembok Elastex Waterproof dari NipponPaint. Pada iklan ini terdapat seorang ibu yang sedang mengadakan acara ulang tahun untuk anaknya seiring berlangsungnya acara cuaca mendung sudah semakin gelap, pertanda akan turun hujan, dia menelpon seorang pawang hujan dan berkata "Mbah, jangan hujan dulu $y a$ " dan hal itu disetujui oleh sang pawang hujan. Begitu pula dengan orang-orang yang menelpon sang pawang hujan selanjutnya. Namun hal ini mendapat protes dari sang istri, sang istri dari pawang hujan mengatakan " $P a$, kenapa hujannya ke sini semua, nanti bocor Pa?", dan sang pawang hujan pun menjawab, "tenang.... 
Tuah Talino

Tahun XIV Volume 14 Nomor 2 Edisi 4 Desember 2020

ISSN 0216-079X E-ISSN 2685-3043

Balai Bahasa Kalimantan Barat

kan ada Elastex. Cat pelapis antibocor dengan kelenturan maksimal'. Apabila dilihat dari konteks situasi yang terjadi dalam iklan tersebut mempunyai maksud bahwa, tidak perlu kita menyewa jasa pawang hujan atau kita tidak perlu takut rumah bocor ketika hujan turun karena dengan menggunakan cat tempok Elastex Waterproof, rumah tidak akan bocor.

Berdasarkan pemaparan diatas, permasalahan dalam penelitian ini adalah bagaimanakah makna kontekstual yang terkandung dalam bahasa iklan cat tembok yang ditayangkan di televisi Indonesia?

\section{METODE}

Pada penelitian ini, penulis menggunakan metode penelitian deskriptif kualitatif. Menurut Djajasudarma (1993:15), metode deskriptif kualitatif yakni data yang dikumpulkan bukanlah angka-angka, dapat berupa kata-kata atau gambaran tentang sesuatu. Sedangkan Nawawi dan Martini (1994: 73) mendefinisikan metode deskriptif sebagai metode yang melukiskan suatu keadaan objektif atau peristiwa tertentu berdasarkan fakta-fakta yang tampak atau sebagaimana mestinya yang kemudian diiringi dengan upaya pengambilan kesimpulan umum berdasarkan fakta-fakta historis tersebut.

Penelitian ini menggunakan iklan cat tembok yang ditayangkan di televisi sebagai objek kajiannya. Data dari penelitian ini adalah kata-kata, frasa, kalimat maupun ungkapan yang terdapat pada iklan cat tembok Elastex Waterproof, Aquaproof, dan Dulux. Penelitian ini akan menggambarkan secara keseluruhan apa yang terkandung dalam tiga iklan cat tembok yang telah disebutkan di atas.

Adapun teknik analisis data yang dilakukan oleh penulis pada penelitian ini sebagai berikut.

1. Menonton dan memahami maksud dari iklan cat tembok yang ditayangkan di televisi.

2. Mencatat apa yang telah ditemukan oleh penulis pada iklan cat tembok tersebut.

3. Mengidentifikasi dan mengklasifikasi makna kontekstual yang terdapat pada iklan cat tembok tersebut, kemudian dianalisis.

4. Membuat kesimpulan berdasarkan data yang telah diperoleh dari hasil menganalisis iklan cat tembok di televisi.

\section{PEMBAHASAN}

Pada subbab ini, penulis akan membahas hasil temuan dari penelitian mengenai makna kontekstual yang terdapat dalam iklan cat tembok yang terdapat di stasiun televisi Indonesia.

Pada bagian analisis data di bawah ini akan dibahas makna kontekstual yang terkandung dalam iklan cat tembok.

\section{Analisis Teks Iklan Cat Tembok Elastex Waterproof}

Pada iklan cat tembok Elastex Waterproof ini terdapat banyak kata hujan, misalnya pada kalimat "Mbah, jangan hujan dulu ya?" kata seorang ibu yang sedang mengadakan acara ulang tahun anaknya, "Hujannya dipending dulu ya Mbah?" kata seorang bapak yang sedang bermain golf, "Mbah, ikannya belum 
kering..." kata seorang ibu yang sedang menjemur ikan. Kemudian, "Pah, hujannya kenapa ke sini semua, nanti bocor Pah" ucap istri dari pawang hujan.

Situasi yang terdapat dalam iklan cat tembok Elastex Waterproof ini adalah seorang pawang hujan yang banyak menerima telpon dari para pelanggannya untuk menunda turunnya hujan, karena mereka sedang ada keperluan ataupun kegiatan di luar rumah, permintaan dari para pelanggan tersebut selalu disanggupi oleh sang pawang hujan, asalkan mereka tidak lupa untuk mentransfer uang (lihat lampiran). Hingga kemudian istri dari sang pawang hujan datang dan melontarkan protes, "Pah, hujannya kenapa ke sini semua, nanti bocor Pah", dan sang pawang hujan dengan santai menjawab, "Tenang, kan ada Elastex".

Pada iklan ini disampaikan dalam bentuk dialog telepon antara sang pawang hujan dengan para pelanggannya, dan juga dialog antara sang pawang hujan dengan istrinya. Kata-kata yang terdapat dalam iklan cat tembok Elastex Waterproof tersebut secara leksikal mengandung makna bahwa jika hujan turun maka aktivitas mereka terhambat dan pekerjaan yang seharusnya selesai pada hari itu juga akan mengalami penundaan karena hujan. Hal ini dibuktikan dengan kalimat "Mbah, jangan hujan dulu ya...." yang diucapkan oleh seorang ibu yang sedang mengadakan acara ulang tahun anaknya.

Secara kontekstual, makna dari semua kalimat yang terdapat dalam iklan cat tembok Elastex Waterproof yang mengenai tentang jangan hujan dulu, dipending dulu ya hujannya, ikan belum kering, dan sebuah protes dari istri sang pawang hujan, kenapa hujannya kesini semua, nanti bocor dan dijawab oleh sang pawang hujan dengan kalimat tenang, kan ada Elastex adalah seharusnya para penonton iklan cat tembok ini tidak perlu khawatir dengan turunnya hujan sebab semua masalah yang datang bersamaan dengan turunnya hujan misalnya bocor ataupun banjir dapat diatasi dengan menggunakan cat tembok Elastex Waterproof. Hal ini juga diperkuat dengan pernyataan pada akhir iklan yang menyebutkan bahwa menggunakan cat tembok Elastex Waterproof dijamin antibocor selama lima tahun. Kemudian adanya keterkaitan antara produk yang sedang dipasarkan dengan tayangan iklan di televisi serta kata-kata yang menarik membuat iklan ini menarik minat para penonton dan mudah diingat. Sehingga apabila para penonton mempunyai kendala yang sama dengan keadaan orang-orang pemeran pada iklan cat tembok tersebut, maka mereka akan mengingat tentang iklan cat tembok ini dan membelinya.

Iklan cat tembok Elastex Waterproof yang terdapat di televisi ini ingin meyakinkan para calon pembeli produk cat tembok tersebut bahwa dengan menggunakan produk cat tembok Elastex Waterproof, semua masalah yang sering dihadapi ketika hujan turun dapat teratasi dengan benar, dan menggunakan cat tembok ini lebih ekonomis sebab lapisan yang diklaim sebagai lapisan antibocor yang terdapat dalam kandungan cat tembok Elastex Waterproof ini tahan hingga lima tahun. Jadi, konsumen yang telah menggunakan cat tembok Elastex Waterproof ini tidak perlu khawatir rumah mereka bocor ketika turun hujan dan juga lebih bisa menghemat uang mereka karena ketahanan dari cat tembok Elastex Waterproof ini. 
Tuah Talino

Tahun XIV Volume 14 Nomor 2 Edisi 4 Desember 2020

ISSN 0216-079X E-ISSN 2685-3043

Balai Bahasa Kalimantan Barat

\section{Analisis Teks Iklan Cat Tembok Dulux Weather Shield}

Pada iklan cat tembok Dulux Weather Shield berupa monolog yang langsung disampaikan kepada penonton dari pembuat iklan yang ingin memasarkan barangnya. "Rumah anda, pribadi anda. Hati-hati dengan perubahan cuaca ekstrim. Cat biasa tidak mampu melindungi dinding dari masalah perubahan cuaca ekstrim. Apa yang terjadi pada rumah anda, akan langsung terasa pada diri anda. Segera ganti dengan Dulux Weather Shield, satu-satunya cat eksterior dengan triple protection. Dulux Weather Shield, perlindungan ekstra melawan cuaca ekstrim. Dijamin!"

Paragraf di atas merupakan transkripsi audio visual dari iklan cat tembok Dulux Weather Shield. Situasi yang terdapat dalam iklan tersebut adalah keadaan rumah yang tidak terawat dan hal itu membuat para penghuninya muram dan tidak bersemangat dalam menjalani kehidupan sehari-hari mereka. Apabila suasana rumah tampak cerah terutama warna cat temboknya, maka kehidupan di sekitarnya pun akan lebih berwarna. Namun, biasanya warna cat tembok akan pudar seiring dengan lamanya waktu penggunaan cat tembok, terkena air hujan, dan juga keadaan cuaca di sekitar tempat tersebut.

Secara leksikal makna kalimat yang terdapat dalam iklan ini adalah cat biasa tidak mampu melindungi dinding dari masalah perubahan cuaca. Kemudian apabila dihubungkan dengan makna kontekstualnya maka tidak ada yang mampu menjaga dinding rumah dari masalah perubahan cuaca ekstrim kecuali Dulux Weather Shield. Cat tembok ini memiliki tiga perlindungan ekstra untuk melawan cuaca ekstrim dan iklan ini juga menyebutkan bahwa apa yang terjadi di sekitar kita terutama di rumah kita akan berpengaruh terhadap kehidupan sehari-hari kita. Kata dijamin pada akhir iklan juga dapat berpengaruh terhadap penonton, kata ini berfungsi untuk meyakinkan penonton bahwa cat tembok merk ini telah terbukti dapat melindungi dinding dari cuaca ekstrim.

Cat tembok Dulux Water Shield merupakan cat eksterior dengan warna yang indah dan kandungan cat yang bagus untuk melindungi tembok dari cuaca ekstrim, seperti panas ataupun hujan yang berlangsung lama. Pembuat iklan ini menggunakan kata-kata persuasif "dijamin" yang memungkinkan pembeli tertarik untuk membeli dan menggunakan produk ini, sebab kata "dijamin" mempresentasikan bahwa produk cat tembok ini telah diujicobakan dengan benar dan hasilnya memuaskan dalam melindungi tembok rumah bagian luar serta warnanya juga variatif. Jadi, kata "dijamin" merupakan inti dari iklan cat tembok ini yang secara tersirat menyatakan bahwa merk cat tembok Dulux Water Shield ini direkomendasikan untuk pengecatan tembok rumah di bagian luar atau eksterior.

\section{Analisis Teks Iklan Cat Tembok Aquaproof}

Pada iklan cat tembok Aquaproof ini disampaikan dengan cara dialog antar tokoh yang ada di dalam iklan tersebut. Kejadian bermula di saat ada seorang lelaki yang mendatangi toko bangunan untuk membeli cat tembok merk Aquaproof, namun karena terbuai oleh promo dari sang penjual jika membeli cat tembok merk lain akan mendapat hadiah payung maka dia membeli cat dengan merk lain tersebut. Namun setelah digunakan di rumahnya dan hujan turun 
Tuah Talino

Tahun XIV Volume 14 Nomor 2 Edisi 4 Desember 2020

ISSN 0216-079X E-ISSN 2685-3043

Balai Bahasa Kalimantan Barat

ternyata rumah lelaki itu tetap saja bocor. Hal itulah yang memicu kemarahan sang istri. "Bukannya ngirit tapi malah nambah duit" kata sang istri sambil marahmarah dan sang suami tidak dapat berkata apa-apa hanya bisa memayungi sang istri agar tidak basah akibat dari bocor di atap rumah mereka.

Secara leksikal, kalimat yang terdapat dalam iklan cat ini adalah tidak bisa irit, tapi malah nambah duit. Sedangkan secara kontekstual kalimat dalam iklan ini bermakna bahwa dengan membeli cat tembok merk lain yang mungkin harganya lebih murah dan mendapatkan iming-iming sebuah hadiah yang menarik sebenarnya malah rugi sebab merk selain Aquaproof belum teruji kualitasnya. Kemudian pada akhir iklan terdapat sebuah kalimat yang diucapkan oleh narator yang berbunyi aku pilih Aquaproof....pada kalimat ini memiliki konteks bahwa aku memilih Aquaproof sebab Aquaproof telah teruji selama puluhan tahun melindungi rumah-rumah di Indonesia.

Pada iklan cat tembok Aquaproof ini, pembuat iklan bermaksud untuk menjelaskan bahwa terbuai oleh promo yang menarik ketika akan membeli cat tembok akan berakibat fatal. Walaupun dengan alasan merk lain lebih murah dan mendapatkan hadiah langsung, namun tetap ada harga ada kualitas. Hal ini sering diucapkan oleh orang-orang yang akan atau sedang membeli sebuah produk tidak masalah harga barang lebih mahal sedikit asalkan kualitasnya bagus, daripada membeli dengan harga murah namun tidak awet atau tidak terjamin kualitasnya. Kalimat "bukannya ngirit tapi malah nambah duit" menjelaskan bahwa dengan menggunakan merk cat tembok selain Aquaproof malah lebih boros karena harus membeli cat tembok dua kali, sebab kualitas cat tembok belum teruji.

Pada ketiga iklan cat tembok yang telah dipaparkan di atas, Elastex Waterproof, Dulux Water Shield, dan Aquaproof menjelaskan bahwa para pembuat iklan menggunakan kata-kata yang persuasif untuk menarik minat para calon pembeli agar pembeli tertarik untuk membeli produk cat yang terdapat dalam iklan-iklan cat tembok tersebut. Pada iklan cat tembok Elastex Waterproof, pembuat iklan cat tembok ini meyakinkan para calon pembeli dengan pernyataan di akhir iklan bahwa menggunakan cat tembok merk ini akan dijamin antibocor selama lima tahun. Hal ini tentu sangat menarik para calon pembeli yang potensial sebab dengan ketahanan cat tembok Elastex Waterproof selama lima tahun, mereka akan lebih berhemat dalam pengeluaran untuk kebutuhan membeli cat tembok rumah mereka.

Kemudian untuk iklan cat tembok Dulux Weather Shield, pembuat iklan menyebutkan kata "dijamin" untuk menegaskan bahwa merk cat tembok ini telah teruji untuk melindungi tembok dari cuaca ekstrim seperti panas dan juga hujan. Pada iklan cat tembok Dulux Water Shield ini juga para penonton iklan diberi informasi bahwa keadaan sekeliling kita maka akan berpengaruh pula terhadap psikologis kita. Sebagai contoh, apabila warna cat tembok rumah kita pudar, maka keseharian orang-orang di dalam ataupun di sekitar rumah tersebut akan ikut muram. Jadi, pembuat iklan mempersuasi para penonton untuk mengganti cat tembok rumah mereka dengan Dulux Water Shield agar hidup mereka lebih berwarna.

Iklan cat tembok yang terakhir dianalisis adalah Aquaproof, pada iklan cat tembok ini salah satu pemeran mengungkapkan "bukannya ngirit tapi malah 
Tuah Talino

Tahun XIV Volume 14 Nomor 2 Edisi 4 Desember 2020

ISSN 0216-079X E-ISSN 2685-3043

Balai Bahasa Kalimantan Barat

nambah duit", hal ini menjelaskan bahwa harga murah dan iming-iming sebuah promo ataupun hadiah yang menarik tidak dapat menjamin kualitas barang tersebut. Hal tersebut malah dapat menjerumuskan kita untuk berlaku boros dan merugi, sebab harus membeli cat tembok untuk kedua kalinya. Pada iklan cat tembok Aquaproof ini, pembuat iklan secara tersirat mengungkapkan bahwa tidak masalah membeli suatu produk dengan harga yang lebih mahal sedikit asal kualitasnya bagus daripada barang dengan harga yang murah, terdapat promo dan mendapat hadiah, ada harga ada kualitas.

\section{PENUTUP}

Berdasarkan penjelasan yang telah dipaparkan oleh penulis di atas tentang iklan cat tembok Elastex Waterproof, Dulux Water Shield, dan Aquaproof, dapat disimpulkan bahwa semua iklan dibuat oleh orang yang akan memasarkan barang dagangannya agar barang dagangannya tersebut dapat dikenal oleh masyarakat dan laris di pasaran, serta semua iklan cat tembok yang telah diteliti dalam artikel ini oleh penulis mempunyai makna leksikal dan juga makna kontekstual.

Selain itu, terdapat hal-hal yang dapat kita pelajari dari tiga iklan cat tembok yang telah dibahas pada artikel ini, bahwa cat tembok dapat memudar seiring dengan berjalannya waktu dan juga dapat dipengaruhi oleh iklim di sekitar tempat tinggal kita tersebut, misalnya panas dan juga hujan. Dari ketiga iklan cat tembok yang dibahas pada artikel ini mengklaim bahwa produknya telah diuji dan dapat melindungi tembok rumah secara maksimal. Kemudian para pembuat iklan menyugesti bahwa keadaan rumah dapat berpengaruh pada penghuninya. Apabila warna cat tembok pudar, maka para penghuninya akan muram. Jadi dengan mengecat tembok secara berkala akan membuat warna tembok tetap bagus dan indah serta kehidupan penghuninya akan berwarna.

Makna kontekstual yang terkandung dalam tiga iklan cat tembok yang telah diteliti dalam artikel ini berupa kata maupun kalimat yang berfungsi untuk menarik konsumen agar membeli produk dari cat tembok tersebut, sebab produkproduk tersebut mempunyai kualitas yang bagus dan teruji walaupun minim promo dan harga yang lebih mahal sedikit sebab ada harga ada kualitas, serta keawetan dari produk-produk cat tembok tersebut yang dapat membuat para pemakainya menjadi hemat dalam hal pengeluaran untuk membeli kebutuhan cat tembok daripada dengan cat tembok lain dengan harga yang murah dan imingiming promo yang menggiurkan tapi kualitas belum teruji dengan benar. Hal ini diperkuat juga dengan pernyataan disetiap akhir iklan yang persuasif guna untuk meyakinkan calon pembeli yang potensial untuk membeli cat tembok yang dipasarkan tersebut.

\section{DAFTAR PUSTAKA}

Alwi, Hasan. (2010). Tata Bahasa Baku Bahasa Indonesia. Jakarta: Balai Pustaka.

Chaer, A. (2007). Linguistik Umum. Jakarta: Rineka Cipta.

Departemen Pendidikan dan Kebudayaan. (2002). Kamus Besar Bahasa Indonesia. Jakarta: Balai Pustaka.

Djajasudarma, Fatimah. (1993). Metode Linguistik: Ancangan Metode Penelitian dan Kajian. Jakarta: Refika Aditama. 
Tuah Talino

Tahun XIV Volume 14 Nomor 2 Edisi 4 Desember 2020

ISSN 0216-079X E-ISSN 2685-3043

Balai Bahasa Kalimantan Barat

Fajriani, Nulla. (2016). Analisis Makna Slogan Iklan Rokok Di Kota Mataram. Skripsi. Universitas Mataram.

Hadari Nawawi \& Mimi Martini. (1994). Penelitian Terapan, Yogyakarta: Gajahmada University.

Jefkins, Frank. (1997). Periklanan. Jakarta: Erlangga.

Kemal, Isthifa. (2013). Makna Kontekstual Bahasa Iklan Rokok di Televisi. Diakses pada tanggal 30 Maret 2018 dari http://download.portalgaruda.org.

Rachmadi, F. (1993). Public Relation dalam Teori dan Praktek. Jakarta: Gramedia Pustaka Utama.

Verhaar, J.W.M. (2012). Asas-asas Linguistik Umum. Yogyakarta: Gadjah Mada University Press.

https://www.youtube.com/watch?v=hitekogAhnQ dilihat pada tanggal 16 mei 2018 pada pukul 21:43 wib.

https://www.youtube.com/watch? $v=Y V i V x k V E O d w$ dilihat pada tanggal 16 Mei 2018 pada pukul 22:00 wib

https://www.youtube.com/watch? $v=Z s 7 p y 1 I t c m w$ dilihat pada tanggal 16 Mei 2018 pada pukul 22:33 wib.

\section{Lampiran}

\section{Iklan cat tembok Elastex Waterproof}

Pada sebuah acara ulang tahun.

Ibu : :Mbah, jangan hujan dulu ya?"

Pawang Hujan: "Iya... beres Bu!"

Di lapangan golf

Bapak : "Hujannya dipending ya Mbah?"

Pawang Hujan: "Siap...."

Di tempat penjemuran ikan

Ibu : "Mbah, ikannya belum kering...."

Pawang Hujan: "Iya... jangan lupa transfer"

Di rumah sang pawang hujan

Istri : "Pah, kenapa hujannya kesini semua, nanti bocor Pah!"

Pawang Hujan: "Tenang, kan ada Elastex!"

Elastex Waterproof, cat pelapis anti bocor dengan kelenturan maksimal.

Narator: "Mbah jangan hujan dulu, belum punya Elastex!"

Jaminan 5 tahun Anti Bocor.

\section{Iklan Dulux Weather Shield}

Rumah anda, pribadi anda. Hati-hati dengan perubahan cuaca ekstrim. Cat biasa tidak mampu melindungi dinding dari masalah perubahan cuaca ekstrim. Apa yang terjadi pada rumah anda, akan langsung terasa pada diri anda. Segera ganti dengan Dulux Weather Shield, satu-satunya cat eksterior dengan triple protection. Dulux Weather Shield, perlindungan ekstra melawan cuaca ekstrim. Dijamin!

\section{Iklan Aquaproof}

Di sebuah toko bangunan

Pembeli (laki-laki) : "Pak, beli Aquaproof"

Penjual : (membangunkan pelayan toko dan memberi isyarat umtuk mengambilkan sebuah cat) 
Tuah Talino

Tahun XIV Volume 14 Nomor 2 Edisi 4 Desember 2020

ISSN 0216-079X E-ISSN 2685-3043

Balai Bahasa Kalimantan Barat

Pembeli : : "Itukan bukan Aquaproof?"

Penjual : "Beli ini dapat hadiah........ (menunjukkan sebuah payung)

Pembeli : "Iyadeh....."

Di rumah sang pembeli cat tadi. Waktu hujan turun, rumah mereka bocor.

Istri : "Bukannya irit tapi malah nambah duit"

Pembeli (Suami) : “......” (dengan menyodorkan payung hadiah dari membeli

cat)

Makanya pilih Aquaproof terbukti selama 30 tahun melindungi rumah Indonesia.

Istri : "Tuhkan Aquaproof terbukti"

Suami : "Iya..."

Aku pilih Aquaproof...... 